\title{
A DEA MODEL WITH A NON DISCRITIONARY VARIABLE FOR OLYMPIC EVALUATION
}

\author{
João Carlos C.B. Soares de Mello*, Lidia Angulo-Meza \\ and Fábio Gomes Lacerda
}

Received December 10, 2009 / Accepted February 15, 2011

\begin{abstract}
In recent years, a lot of work has been done dealing with alternative performance rankings for the Olympic Games. Almost all of these works use Data Envelopment Analysis (DEA). Generally speaking, those works can be divided into two categories: Pure rankings with unitary input models and relative rankings with classical DEA models; both output oriented. In this paper we introduce an approach taking into account the number of athletes as a proxy to the country investment in sports. This number is an input for a DEA model, and the other input is the population of the country. We have three outputs, the number of gold, silver and bronze medals earned by each country. Contrary to the usual approach in the literature, our model is not output oriented. It is a non-radial DEA model oriented to the "number of athletes" input, as our goal is not a countries' ranking. We intend to analyse whether the number of athletes competing for each country accords with the number of won medals. For this analysis, we compare each country with its benchmarks. The Decision Making Units (DMU) are all the countries participating in the Beijing Olympic Games, including those that did not earn a single medal. We use a BCC model and we compare each DMU's target with the number of athletes who have won, at least one medal.
\end{abstract}

Keywords: Data Envelopment Analysis, olympic games, sport evaluation.

\section{INTRODUCTION}

Performance evaluation has been widely studied in sport for the last 25 years (Nevill et al., 2008). In the case of the Olympic Games the rank of the nations is traditionally carried out with the socalled Lexicographic Multicriteria Method (Lins et al., 2003). In this very paper the drawbacks of the Lexicographic Method are pointed out and a new ranking is suggested.

There are already some other approaches using Data Envelopment Analysis (Charnes et al., 1978). The very first one was proposed by Lozano et al. (2002). They used population and GNP as inputs and the medals as outputs. In a similar approach, Lins et al. (2003) built a new

*Corresponding author

Departamento de Engenharia de Produção, Universidade Federal Fluminense. E-mail: jcsmello@pq.cnpq.br 
model taking in account one more constraint: the total amount of medals is a constant. This resulted in the development of a new model, the so-called Zero Sum Gains DEA model (ZSGDEA). Churilov \& Flitman (2006) used DEA to establish a ranking, the inputs of which were some social economical variables (population, GDP, DEL index and IECS index). The outputs were some linear combination of the number of medals earned by each country. Li et al. (2008) have used GDP per capita and population as inputs and impose different weight restrictions for each DMU, according to a previous country categorization.

Wu et al. (2008, 2009b) use a cross Evaluation DEA model to establish an Olympic Ranking. They came across the same problem described in Soares de Mello et al. (2002): the existence of negative efficiencies in the BCC-DEA model. They solved the problem with the same approach used by Soares de Mello et al. (2008b). Wu et al. (2009a) have used the results of Wu et al. (2009b) to study a Nash equilibrium in a BCC-DEA Cross Evaluation for the Olympic Ranking.

Zhang et al. (2009) used lexicographic preferences instead of weight restrictions (Allen et al., 1997) to establish a DEA based ranking for the Athens Olympic Games.

All the works mentioned hereabove take into account the results in the Olympics and the socio economical conditions of each country. Models using DEA and nothing but medals won by each country were presented by Soares de Mello et al. (2004), Hai et al. (2007), Soares de Mello et al. (2008a, 2009) and Soares de Mello et al. (2008c).

Despite their important differences, the papers cited hereabove have some common points. The first one is that those papers evaluate only countries that have earned medals. In other words, the units evaluated by DEA (Decision Making Units - DMU) are the countries that have won at least one medal. The other point in common in all those papers is the DMU's objective: to maximize some combination of the number of earned medals.

In this paper we are not interested in Olympic Rankings. We wish to study whether each country's number of competitors is reasonable when compared to all the other countries. Moreover, we will evaluate all participating countries in the Beijing's Olympic Games including those that have won no medals. This is possible because of a mathematical property of the DEA model with variable returns to scale, the so-called BCC DEA model (Banker et al., 1984). In that model, a DMU may still be efficient even if all its outputs have no value. Likewise the majority of models concerning Olympic evaluation, our model will have three outputs: number of gold, silver and bronze medals. The model will have two inputs: the population and the number of competitors for each country. As we intend to evaluate the dimension of each country's team we will orient the DEA model only to input. This leads to the study of non radial DEA models. These models will be summarized in section 2. Section 3 presents the DEA model used in our study. The results are presented in section 4 and in Section 5 we present some final comments. 


\section{DATA ENVELOPMENT ANALYSIS MODELS WITH NON DISCRETIONARY VARIABLES}

The classical BCC input oriented model (Banker et al., 1984) in the envelopment formulation is presented in (1).

$$
\begin{aligned}
& \text { Min } h_{0} \\
& \text { subject to } \\
& h_{0} x_{i 0}-\sum_{k=1}^{n} x_{i k} \lambda_{k} \geq 0, \quad \forall i \\
& -y_{j 0}+\sum_{k=1}^{n} y_{j k} \lambda_{k} \geq 0, \quad \forall j \\
& \sum_{k=1}^{n} \lambda_{k}=1 \\
& \lambda_{k} \geq 0, \quad \forall k
\end{aligned}
$$

where $h_{0}$ is the efficiency of DMU 0 , the DMU under evaluation; $x_{i k}$ is the input $i$ of DMU $k ; y_{j k}$ is the output $j$ of DMU $k ; \lambda_{k}$ is the share of DMU $k$ for DMU 0 's target. According to the model, when an inefficient DMU achieves efficiency, all its inputs are proportionally reduced. Should we wish to achieve efficiency changing only the value of a single input, we ought to use model (2). This model was introduced by Banker \& Morey (1986) and can be seen as a particular case of the MORO model (Lins et al., 2004; Quariguasi Frota Neto \& Angulo-Meza, 2007), when all but one factor are not allowed to be changed.

$$
\begin{aligned}
& \text { Min } h_{0} \\
& \text { subject to } \\
& h_{0} x_{v 0}-\sum_{k=1}^{n} x_{v k} \lambda_{k} \geq 0, \\
& x_{i 0}-\sum_{k=1}^{n} x_{i k} \lambda_{k} \geq 0, \quad \forall i \neq v \\
& -y_{j 0}+\sum_{k=1}^{n} y_{j k} \lambda_{k} \geq 0, \quad \forall j \\
& \sum_{k=1}^{n} \lambda_{k}=1 \\
& \lambda_{k} \geq 0, \quad \forall k
\end{aligned}
$$

In model (2), $x_{v k}$ is the variable that can change. 


\section{MODELLING}

As mentioned earlier, the main goal of our study is to evaluate the performance of the Olympic teams in Beijing 2008 Games, taking into account the number of athletes for each and every country. We use as outputs the number of gold, silver and bronze medals won by each country. The controlled input is the number of athletes in each team, which is a proxy for the country investment in sports. This input has been proved to be an important contextual variable to explain the performance of the countries in the Olympics (Gomes \& Souza, 2009). As an uncontrolled input we use each country's population. We have restrained the weight of each medal as in Soares de Mello et al. (2008a, 2008c, 2009), i.e. the gold medal weight is no lower than the silver medal weight, which again is no lower than the bronze medal weight. Moreover, the difference of weights between the gold and the silver medals is not lower than the difference of weights between the silver and bronze medals. Model (3) is the linear programme for a given country.

$$
\begin{aligned}
& \text { Min } h_{0} \\
& \text { subject to } \\
& x_{P O P O}-\sum_{j=1}^{n} \lambda_{j} x_{P O P j} \geq 0 \\
& h_{0} x_{A T H L O}-\sum_{j=1}^{n} \lambda_{j} x_{A T H L j} \geq 0 \\
& y_{G} \leq \sum_{j=1}^{n} \lambda_{j} y_{G j}-\gamma_{1}-\gamma_{3} \\
& y_{S} \leq \sum_{j=1}^{n} \lambda_{j} y_{S j}+\gamma_{1}-\gamma_{2}+2 \gamma_{3} \\
& y_{B} \leq \sum_{j=1}^{n} \lambda_{j} y_{B j}+\gamma_{2}-\gamma_{3} \\
& \sum_{j=1}^{n} \lambda_{j}=1 \\
& \gamma_{j} \geq 0, \quad \forall j
\end{aligned}
$$

In model (3), $h_{o}$ is the efficiency of the observed country; $\gamma_{j}$ is the share of country $j$ for observed country $o ; x_{P O P O}$ is the observed country's population; $x_{A T H O}$ is each country's number of athletes; $y_{G}, y_{S}$ and $y_{B}$ are the observed country's number of gold, silver and bronze medals; $y_{G j}, y_{S j}$ and $y_{B j}$ are country $j$ 's number of gold, silver and bronze medals. Variables $\gamma_{1}, \gamma_{2}$ and $\gamma_{3}$ are the dual variables corresponding to the weight restrictions in the primal problem (multipliers formulation). 


\section{RESULTS}

Table 1 presents the results for some countries, using model (3). In this table, the "ideal" number of athletes is the non-radial target for each country. It is obtained by multiplying the efficiency by the number of athletes. The Number of Medal Winners, or number of medallists, represents how many athletes did a country need to win all its medals. For instance, if a country wins eight medals with only one athlete it would have number of medal winners equal to one. On the other hand if a country wins a medal in a collective sport, for instance, soccer, it would lead at least eleven athletes to win that medal.

We may observed that for some countries the ideal number of athletes is not an integer. Almost all researchers who work with output oriented models in DEA for Olympic Evaluation do not take into account that the number of medals cannot be a fractionary number. The only exception is the work of Wu et al. (2010). In our case, we will not deal with the problem of non integer values. We assume that in the case of a non integer target, the DMU may use the nearest integer.

Obviously it is impossible to know beforehand who will win an Olympic medal and who will not. So the "Ideal Team" must not be equal to the number of medallists. The "Ideal Team" is, in most cases, larger than the number of medal winners. So, there are no winners in the "Ideal team". There are some exceptions. For Iceland, Brazil, Argentina, Nigeria and Serbia the "Ideal Team" is smaller than the number of medallists. For such countries it is impossible to reduce the number of athletes down to the ideal number and still win the same number of medals. This result might vindicate the idea that the sports investment policy might not be the best policy for those countries.

As China has won the largest number of gold medals, a well known property of the BCC-DEA model (Ali, 1993) ensures that this country is efficient irrespective of input levels.

In Table 1, Niger, Burundi, Central African Republic, Gabon, Belize, Dominica, Nauru and Tuvalu have won no medals yet they are DEA efficient. This is because Tuvalu has the smallest population and the others have only one competing athlete. Due to another well known BCCDEA model property (Ali, 1993), these DMUs are efficient irrespective of output levels.

China's fielding many non-winning athletes makes this analysis render larger other countries' ideal teams; several countries having won no medals, confirms it. Both enhance the Olympics ideal.

As mentioned, ideal teams need not necessarily include winners.

Table 2 shows the benchmarks for the countries for which the "Ideal Team" is smaller than the actual number of medallists. In this table, the most important benchmark is the DMU with the biggest contribution to the non-radial target, i.e., the biggest $\lambda$ in model (3).

Except for Iceland, those countries' benchmarks are African. China is in fact Brazil's secondary benchmark. However, she profited from the home advantage phenomenon (Balmer et al., 2001; 2003), which may render her not really a true benchmark despite being a mathematical one. 
Table 1

\begin{tabular}{|c|c|c|c|c|c|c|c|}
\hline Country & Gold & Silver & Bronze & $\begin{array}{c}\text { Number of } \\
\text { athletes }\end{array}$ & $\begin{array}{c}\text { Number of } \\
\text { medal winners }\end{array}$ & $\begin{array}{l}\text { "Ideal" number } \\
\text { of athletes }\end{array}$ & $\begin{array}{c}\text { DEA } \\
\text { efficiency }\end{array}$ \\
\hline China & 51 & 21 & 28 & 564 & 159 & 564.00 & 1.0000 \\
\hline USA & 36 & 38 & 36 & 629 & 272 & 629.00 & 1.0000 \\
\hline Russia & 23 & 21 & 28 & 411 & 134 & 411.00 & 1.0000 \\
\hline United Kingdom & 19 & 13 & 15 & 297 & 59 & 297.00 & 1.0000 \\
\hline Australia & 14 & 15 & 17 & 439 & 85 & 439.00 & 1.0000 \\
\hline Jamaica & 6 & 3 & 2 & 56 & 13 & 56.00 & 1.0000 \\
\hline Kenya & 5 & 5 & 4 & 52 & 14 & 52.00 & 1.0000 \\
\hline Ethiopia & 4 & 1 & 2 & 21 & 5 & 21.00 & 1.0000 \\
\hline Cuba & 2 & 11 & 11 & 152 & 47 & 152.00 & 1.0000 \\
\hline Zimbabwe & 1 & 3 & 0 & 13 & 1 & 13.00 & 1.0000 \\
\hline Panama & 1 & 0 & 0 & 5 & 1 & 5.00 & 1.0000 \\
\hline Bahamas & 0 & 1 & 1 & 22 & 5 & 22.00 & 1.0000 \\
\hline Armenia & 0 & 0 & 6 & 23 & 6 & 23.00 & 1.0000 \\
\hline Togo & 0 & 0 & 1 & 2 & 1 & 2.00 & 1.0000 \\
\hline Niger & 0 & 0 & 0 & 1 & 0 & 1.00 & 1.0000 \\
\hline Burundi & 0 & 0 & 0 & 1 & 0 & 1.00 & 1.0000 \\
\hline $\begin{array}{c}\text { Central African } \\
\text { Republic }\end{array}$ & 0 & 0 & 0 & 1 & 0 & 1.00 & 1.0000 \\
\hline Gabon & 0 & 0 & 0 & 1 & 0 & 1.00 & 1.0000 \\
\hline Belize & 0 & 0 & 0 & 1 & 0 & 1.00 & 1.0000 \\
\hline Dominica & 0 & 0 & 0 & 1 & 0 & 1.00 & 1.0000 \\
\hline Nauru & 0 & 0 & 0 & 1 & 0 & 1.00 & 1.0000 \\
\hline Tuvalu & 0 & 0 & 0 & 3 & 0 & 3.00 & 1.0000 \\
\hline Mongolia & 2 & 2 & 0 & 21 & 4 & 20.96 & 0.9979 \\
\hline Belarus & 4 & 5 & 10 & 123 & 28 & 113.50 & 0.9228 \\
\hline$\ldots$ & $\ldots$ & $\ldots$ & $\ldots$ & $\ldots$ & $\ldots$ & $\ldots$ & $\ldots$ \\
\hline Iceland & 0 & 1 & 0 & 19 & 14 & 5.81 & 0.3056 \\
\hline$\ldots$ & $\ldots$ & $\ldots$ & $\ldots$ & $\ldots$ & $\ldots$ & $\ldots$ & $\ldots$ \\
\hline Brazil & 3 & 4 & 8 & 265 & 74 & 57.95 & 0.2187 \\
\hline$\ldots$ & $\ldots$ & $\ldots$ & $\ldots$ & $\ldots$ & $\ldots$ & $\ldots$ & $\ldots$ \\
\hline Argentina & 2 & 0 & 4 & 137 & 53 & 19.29 & 0.1408 \\
\hline Nigeria & 0 & 1 & 3 & 82 & 24 & 11.50 & 0.1402 \\
\hline$\ldots$ & $\ldots$ & $\ldots$ & $\ldots$ & $\ldots$ & $\ldots$ & $\ldots$ & $\ldots$ \\
\hline Serbia & 0 & 1 & 2 & 88 & 15 & 9.33 & 0.1060 \\
\hline$\ldots$ & $\ldots$ & $\ldots$ & $\ldots$ & $\ldots$ & $\ldots$ & $\ldots$ & $\ldots$ \\
\hline Angola & 0 & 0 & 0 & 27 & 0 & 1.00 & 0.0370 \\
\hline Hong Kong & 0 & 0 & 0 & 35 & 0 & 1.00 & 0.0286 \\
\hline South Africa & 0 & 1 & 0 & 133 & 1 & 3.50 & 0.0263 \\
\hline Egypt & 0 & 0 & 1 & 76 & 1 & 2.00 & 0.0263 \\
\hline Venezuela & 0 & 0 & 1 & 92 & 1 & 2.00 & 0.0217 \\
\hline
\end{tabular}


Table 2

\begin{tabular}{|c|c|c|}
\hline Country & $\begin{array}{c}\text { Most important } \\
\text { benchmark }\end{array}$ & $\begin{array}{c}\text { Other } \\
\text { benchmarks }\end{array}$ \\
\hline Iceland & Nauru & Jamaica and Armenia \\
\hline Brazil & Kenya & China \\
\hline Argentina & Zimbabwe & Ethiopia and Kenya \\
\hline Nigeria & Ethiopia and Togo & - \\
\hline Serbia & Zimbabwe & Togo and Ethiopia \\
\hline
\end{tabular}

\section{FINAL COMMENTS}

We have presented in this paper a BCC-DEA model to evaluate countries at the Olympic Games. It is important to point out that we are not interested in rankings, but in sports evaluation. We have obtained the Ideal number of athletes for each country. This Ideal number includes winners and non-winners, preserving the "De Coubertin" Olympic spirit. However, the main result is that this does not apply for some countries. That is the case of Brazil, Nigeria, Serbia, Argentina and Iceland. As stated earlier, if those countries succeeded in reducing the number of their athletes, they would not be able to win the same number of medals. Countries whose "ideal" team is smaller than their number of all medal-winning athletes might have an inefficient policy of investment in sport (poor resource allocation). Those countries invest probably too much in team sports such as football (Argentina), volleyball (Brazil) or water polo (Iceland).

The above mentioned "inefficient" policy obtains only when the Olympic Evaluation is based on the total number of medals. Evaluations based on the number of medals won in different sports (Soares de Mello et al., 2009) might have different results. It may also be noticed that qualifying a sports policy investment as inefficient does not take into account "national pride" ascribed to some sports in some countries and of course we ought not to neglect the important of the national pride in the Olympics (van Hilvoorde et al., 2010).

It is interesting to notice that those benchmark countries are mainly African. These are particularly strong countries in individual sports.

Future studies may explore these conclusions and try to identify which are the most profitable sport investments for each country. And we may take also into account that the number of athletes is an integer value and we will use FDH models (Deprins et al., 1984) or integer valued DEA models (Kazemi Matin \& Kuosmanen, 2009; Lozano \& Villa, 2006; Wu et al., 2010).

\section{ACKNOWLEDGMENTS}

We are grateful to CNPq and FAPERJ for their financial support. 


\section{REFERENCES}

[1] ALI AI. 1993. Streamlined computation for data envelopment analysis. European Journal of Operational Research, 64: 61-67.

[2] Allen R, Athanassopoulos A, Dyson RG \& Thanassoulis E. 1997. Weights restrictions and value judgements in data envelopment analysis: Evolution, development and future directions. Annals of Operations Research, 73: 13-34.

[3] Balmer NJ, Nevill AM \& Williams AM. 2001. Home advantage in the winter olympics (19081998). Journal of Sports Sciences, 19(2): 129-139.

[4] Balmer NJ, Nevill AM \& Williams AM. 2003. Modelling home advantage in the summer olympic games. Journal of Sports Sciences, 21(6): 469-478.

[5] Banker RD, Charnes A \& Cooper WW. 1984. Some models for estimating technical scale inefficiencies in data envelopment analysis. Management Science, 30(9): 1078-1092.

[6] BANKer RD \& MOREY RC. 1986. Efficiency analysis for exogenously fixed inputs and outputs. Operations Research, 34(4): 513-521.

[7] Charnes A, Cooper WW \& Rhodes E. 1978. Measuring the efficiency of decision-making units. European Journal of Operational Research, 2(6): 429-444.

[8] Churilov L \& Flitman A. 2006. Towards fair ranking of olympics achievements: The case of sydney 2000. Computers and Operations Research, 33(7): 2057-2082.

[9] Deprins D, Simar L \& Tulkens H. 1984. Measuring labor inefficiency in post offices. In: MarCHANd M, Pestieau P \& TulKens H. (Eds.), The performance of public enterprises: Concepts and measurements, Amsterdam: North-Holland, 243-267.

[10] Gomes EG \& Souza GDS. 2009. Two stage models to assess the significance of contextual variables on the efficiency of olympic games winning countries. In: Second IMA International Conference Mathematics in Sports, at Groningen.

[11] HAI HL. 2007. Using vote-ranking and cross-evaluation methods to assess the performance of nations at the olympics. WSEAS Transactions on Systems, 6(6): 1196-1205.

[12] Kazemi Matin R \& Kuosmanen T. 2009. Theory of integer-valued data envelopment analysis under alternative returns to scale axioms. Omega, 37(5): 988-995.

[13] Li Y, Liang L, Chen Y \& Morita H. 2008. Models for measuring and benchmarking olympics achievements. Omega, 36(6): 933-940.

[14] Lins MPE, Angulo-Meza L \& Da Silva ACM. 2004. A multi-objective approach to determine alternative targets in data envelopment analysis. Journal of the Operational Research Society, 55(10): 1090-1101.

[15] Lins MPE, Gomes EG, Soares de Mello JCCB \& Soares de Mello AJR. 2003. Olympic ranking based on a zero sum gains dea model. European Journal of Operational Research, 148(2): 312-322.

[16] Lozano S \& Villa G. 2006. Data envelopment analysis of integer-valued inputs and outputs. Computers and Operations Research, 33(10): 3004-3014. 
[17] Lozano S, Villa G, Guerrero F \& Cortés P. 2002. Measuring the performance of nations at the summer olympics using data envelopment analysis. Journal of the Operational Research Society, 53(5): 501-511.

[18] Nevill A, AtKinson G \& Hughes M. 2008. Twenty-five years of sport performance research in the journal of sports sciences. Journal of Sports Sciences, 26(4): 413-426.

[19] Quariguasi Frota Neto J \& Angulo-Meza L. 2007. Alternative targets for data envelopment analysis through multi-objective linear programming: Rio de Janeiro odontological public health system case study. Journal of the Operational Research Society, 58: 865-873.

[20] Soares de Mello JCCB, Angulo-Meza L \& Branco da Silva BP. 2008a. Some rankings for the athens olympic games using dea models with a constant input. Investigação Operacional, 8(1): 77-89.

[21] Soares de Mello JCCB, Angulo-Meza L \& Branco da Silva BP. 2009. A ranking for the olympic games with unitary input dea models. IMA Journal Management Mathematics, 20(2): 201-211.

[22] Soares de Mello JCCB, Angulo-Meza L, Gomes EG \& Biondi Neto L. 2008b. Alguns paradoxos em modelos dea-bcc: Eficiências negativas e inexistência de retornos de escala. Paper read at XXVIII ENEGEP, at Rio de Janeiro.

[23] Soares de Mello JCCB, Gomes EG, Angulo-Meza L \& Biondi Neto L. 2008c. Cross evaluation using weight restrictions in unitary input dea models: Theoretical aspects and application to olympic games ranking. WSEAS Transactions on Systems, 7(1): 31-39.

[24] Soares de Mello JCCB, Gomes EG, Angulo-Meza L, Biondi Neto L \& Coelho PhG. 2004. A modified dea model for olympic evaluation. In XII Congreso Latino-Iberoamericano de Investigación de Operaciones y Sistemas - CLAIO 2004, at Havana.

[25] Soares de Mello JCCB, Lins MPE \& Gomes EG. 2002. Construction of a smoothed dea frontier. Pesquisa Operacional, 28(2): 183-201.

[26] VAn Hilvoorde I, Elling A \& Stokvis R. 2010. How to influence national pride? The olympic medal index as a unifying narrative. International Review for the Sociology of Sport, 45(1): 87-102.

[27] Wu J, Liang L \& Chen Y. 2009a. Dea game cross-efficiency approach to olympic rankings. Omega, 37(4): 909-918.

[28] WU J, LiAng L, Wu D \& YANG F. 2008. Olympics ranking and benchmarking based on cross efficiency evaluation method and cluster analysis: The case of sydney 2000. International Journal of Enterprise Network Management, 2(4): 377-392.

[29] Wu J, Liang L \& YAng F. 2009b. Achievement and benchmarking of countries at the summer olympics using cross efficiency evaluation method. European Journal of Operational Research, 197(2): 722-730.

[30] WU J, ZHOU Z \& LiANG L. 2010. Measuring the performance of nations at beijing summer olympics using integer-valued dea model. Journal of Sports Economics, 11(5): 549-566.

[31] Zhang D, Li X, Meng W \& LiU W. 2009. Measuring the performance of nations at the olympic games using dea models with different preferences. Journal of the Operational Research Society, 60(7): 983-990. 